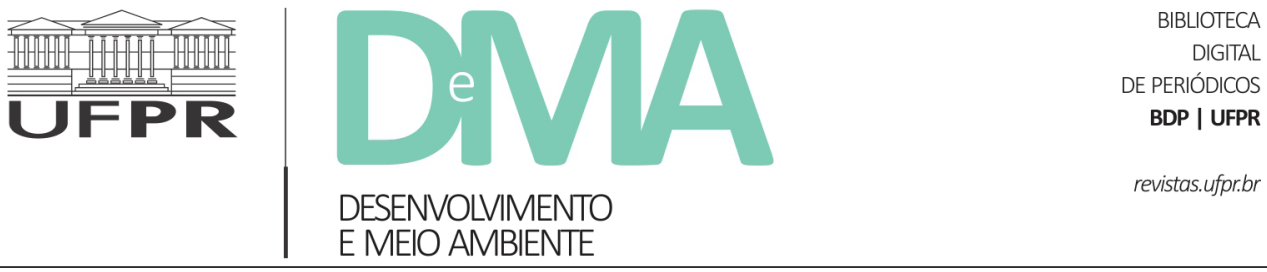

\title{
Movimento e contramovimento e as configurações do campo político em torno da utilização dos agrotóxicos no Brasil
}

\section{Movement and countermovement and the configurations of the political field around the use of pesticides in Brazil}

\author{
Joana Tereza Vaz de MOURA ${ }^{1 *}$, Cimone ROZENDO${ }^{1}$, Marcio Vilela de OLIVEIRA ${ }^{1}$ \\ ${ }^{1}$ Universidade Federal do Rio Grande do Norte (UFRN), Natal, RN, Brasil. \\ *E-mail de contato: joanatereza@gmail.com
}

Artigo recebido em 8 de julho de 2020, versão final aceita em 20 de outubro de 2020, publicado em 22 de dezembro de 2020.

RESUMO: $\quad$ Na última década, o debate sobre o uso dos agrotóxicos tem se acirrado no Brasil em razão do retorno do Projeto de Lei 6.299/02 à pauta parlamentar. De iniciativa da "bancada ruralista", o PL visa flexibilizar a legislação vigente, considerada um obstáculo ao desenvolvimento econômico do setor do agronegócio, permitindo a intensificação da utilização dos agrotóxicos. Em contraposição a esse movimento, diversas organizações sociais e de saúde se articularam na "Campanha Permanente Contra Agrotóxicos e Pela Vida" sendo uma de suas estratégias, a proposição do PL 6670/2016, cujo objetivo é limitar o uso dos referidos produtos. Essas disputas configuram um campo político importante, objeto de análise deste artigo. Partindo das concepções de movimento e contramovimento, oriundas da teoria dos movimentos sociais, procurou-se compreender as relações de enfrentamento entre esses grupos por meio dos repertórios discursivos mobilizados para conquistar a opinião pública e de suas estratégias políticas contra e a favor das Leis. Utilizou-se como fontes de pesquisa: entrevistas; depoimentos de representantes desses grupos, disponíveis em jornais, revistas, sites, audiências públicas; e o documento dos PLs. Identificou-se que a relação movimento/contramovimento trouxe impactos institucionais significativos. Acordos entre o Estado e os empresários do agronegócio favoreceram mudanças na legislação de agrotóxicos intensificando a liberação de novos produtos, rebaixando o sistema de classificação de toxicidade admitindo, inclusive, produtos banidos em outros países. Nesse processo, contribuíram os esforços para construir uma imagem positiva do setor por meio de coalizões políticas, com forte apelo midiático e grande lobby político. De modo similar, mas com menor incidência, o contramovimento estabeleceu alianças internacionais importantes mobilizando a opinião pública e conseguiu implementar políticas restritivas de uso em âmbito municipal e estadual.

Palavras-chave: PL do veneno; Campanha Permanente Contra os Agrotóxicos; agrotóxicos; campo político; movimento; contramovimento. 
ABSTRACT: In the last decade, the debate on the use of pesticides has been intensified in Brazil due to the return of Bill 6,299 / 02 to the parliamentary agenda. The initiative of the "ruralist bank", the PL aims to make the current legislation more flexible, considered an obstacle to the economic development of the agribusiness sector, allowing the intensified use of pesticides. In opposition to this movement, several social and health organizations joined in the "Permanent Campaign Against Pesticides and For Life" being one of its strategies, the proposition of PL 6670/2016, whose objective is to limit the use of these products. These disputes constitute an important political field, the object of analysis of this article. Starting from the conceptions of movement and countermovement, derived from the theory of social movements, we tried to understand the coping relationships between these groups through the discursive repertoires mobilized to conquer public opinion and their political strategies against and in favor of the Laws. We used as sources of research: interviews, testimonies of representatives of these groups, available in newspapers, magazines, websites, public hearings and the PL document. It was identified that the movement / countermovement relationship brought significant institutional impacts. Agreements between the State and agribusiness have favored changes in the legislation on pesticide by intensifying the release of new products, lowering the toxicity classification system by admitting products banned in other countries. In this process, efforts to build a positive image of the sector through political coalitions, with strong media appeal and great political lobby have contributed. In similar way, but with less incidence, the countermovement has established important international alliances mobilizing public opinion and managed to implement restrictive policies for use at the municipal and state levels.

Keywords: PL of Poison; Permanent Campaign Against Pesticides and For Life; pesticides; political field; movement; countermovement.

\section{Introdução}

A articulação da "bancada ruralista" e de entidades ligadas ao setor patronal rural no Brasil para recolocar em pauta o Projeto de Lei 6.299/02, denominado pelas entidades ambientalistas de "Pacote do Veneno", vem produzindo sistemáticas mobilizações de movimentos ligados à agroecologia, saúde, meio ambiente e segurança alimentar, aqui denominados de contramovimento social.

A partir da publicação do Dossiê da Associação Brasileira de Saúde Coletiva (ABRASCO), em 2012, denunciando "a escalada ascendente de uso de agrotóxicos no país e a contaminaçï̈ do ambiente e das pessoas dela resultante, com severos impactos sobre a saúde pública" (ABRASCO, 2012, p.
11), várias entidades se organizaram por meio da "Campanha Permanente Contra os Agrotóxicos e Pela Vida" para sensibilizar a opinião pública com relação ao uso abusivo dos agrotóxicos no país, configurando-se assim um contramovimento. Em 2015, o Dossiê ganhou uma nova edição apresentando evidências científicas da correlação direta entre uso de agrotóxicos e problemas de saúde. A essas publicações se associaram a divulgação de material audiovisual, como os documentários produzidos por Silvio Tendler: "O Veneno tá na mesa 1 e 2" com grande repercussão pública.

Tanto os apoiadores da "Campanha Permanente Contra os Agrotóxicos" quanto os representantes do agronegócio procuram usar repertórios discursivos que mobilizam imagens e símbolos

\footnotetext{
${ }^{1}$ A "bancada ruralista" refere-se à Frente Parlamentar da Agricultura (FPA) e agrega "prioritariamente grandes proprietários de terras e empresários rurais e agroindustriais e parlamentares representantes de estados em regiões de conflitos de terra e nas áreas de novas fronteiras agrícolas. Reúne também parlamentares identificados com uma visão de mundo conservadora” (Bruno, 2015, p. 9).
} 
na mídia buscando impor seus enquadramentos simbólicos sobre a questão dos agrotóxicos e sensibilizar apoiadores dentro e fora do Estado (Meyer \& Staggenborg, 1996). Nessa luta pela construção de narrativas, esses grupos aliam-se a intelectuais para chancelar cientificamente suas pautas e conquistar maior legitimidade, num verdadeiro ciclo de consagração de ideias, num processo constante de produção de verdades (Bourdieu, 2002). Além disso, buscam apoio por intermédio de canais tradicionais como o lobby parlamentar, ações judiciais e alianças internacionais.

Portanto compreende-se que o campo político (Bourdieu, 2011) formado em torno das disputas de um novo marco regulatório para os agrotóxicos constitui um importante objeto de análise que nos permite entender históricas tensões que se reproduzem para além desse campo e examinar a pertinência da abordagem do movimento/contramovimento para o contexto brasileiro.

Considerando a intensidade dessas disputas, o artigo procura analisar como se configura esse campo político, os repertórios discursivos mobilizados pelos diferentes agentes nesses enfrentamentos e quais são seus efeitos políticos.

Do ponto de vista metodológico, investiu-se na construção de um modelo de análise qualitativo, recorrendo a métodos e técnicas que permitiram observar as particularidades das tomadas de posição a partir dos discursos de representantes dos dois grupos. Foram utilizados como fonte de pesquisa os depoimentos dos representantes desses grupos nos espaços legislativos, em audiências públicas, em entrevistas em sites, blogs, jornais e revistas, bem como os PLs. Ao centrar a análise nas narrativas, evidenciou-se as estratégias usadas pelos ativistas para criar coalizões e influenciar a agenda pública (Polletta \& Gardner, 2015). Argumenta-se que a elaboração dos diferentes repertórios discursivos se constituiu um elemento central nesse campo político, legitimando e ressignificando valores sistematicamente, ora mobilizando a mídia, ora a ciência, valendo-se de artifícios jurídicos, além do habitual lobby político.

\section{Movimentos sociais, Estado e contramovimentos: dinâmicas relacionais na configuração do campo político}

As análises das relações entre movimentos sociais e Estado no Brasil já têm um longo percurso acadêmico que se inicia, na década de 1990, com a expansão sistemática de debates sobre a participação social nos conselhos gestores de políticas públicas, orçamentos participativos, fóruns temáticos, entre outros espaços. Esses estudos, de maneira geral, mostraram que a inserção de representantes da sociedade civil em canais participativos modificou a maneira de se elaborar e implementar políticas públicas, mas também as dinâmicas internas das organizações sociais. Os trabalhos mais recentes (anos 2000) se preocuparam em entender como os militantes inseridos em estruturas da burocracia estatal influenciaram as dinâmicas institucionais, focando especialmente nos movimentos sociais progressistas. Autores como Silva \& Oliveira (2011), Abers et al. (2014), Carlos (2015) e Pereira (2020) apontaram que essa inserção produziu resultados importantes para as políticas públicas, ao mesmo tempo em que alteram as percepções dos movimentos sociais com relação às dinâmicas estatais. Ao contrário de perspectivas anteriores que concebiam tal processo como forma de cooptação 
dos movimentos sociais pelo Estado, essa literatura produziu significantes contribuições ao debate mostrando que existe um "complexo padrão de relações entre sociedade civil e Estado, mediadas por partidos politicos" (Silva \& Oliveira, 2011, p. 86), criando um novo modo de comunicação e negociação "baseadas em protestos e outros encontros, menos públicos e mais personalizados, entre Estado e representantes de movimentos sociais" (Abers et al., 2014, p. 326).

Apesar de terem oferecido um arsenal analítico importante para entender as dinâmicas colaborativas entre movimentos sociais e Estado e, mais recentemente, trazendo à tona a necessidade de incorporar à discussão o papel central do chefe do Executivo (Pereira, 2020), esses trabalhos negligenciaram "os processos de organização e mobilização social contestatória de grupos dominantes e conservadores" (Silva \& Pereira, 2020, p. 1). Nessa perspectiva, as reflexões se centravam sobre a organização interna dos movimentos, suas relações com o Estado e suas estratégias e repertórios utilizados e, portanto, pouco se aprofundou sobre relações dos movimentos com seus opositores. Entende-se que o conceito de contramovimento pode oferecer ferramentas analíticas importantes na compreensão das relações de conflito entre organizações sociais, opositores e o Estado, formando, assim uma tríade movimento social-contramovimento-Estado (Szwako, 2014).

Segundo Lo (1982, p. 119), "a definição de contramovimento como parte de um par de interação de movimentos foca a atenção em como a interação afeta valores, objetivos e táticas do contramovimento". Contramovimentos sociais, então, podem ser definidos como:

[...] Redes de indivíduos e organizações que comparti- lham muitos dos objetos de interesse dos movimentos sociais aos quais se opõem. Eles fazem demandas concorrentes ao Estado em questões políticas e de política pública (...) e competem pela atenção da mídia e do público (Meyer \& Staggenborg, 1996, p. 1632 apud Silva, 2020, p. 4).

Esse conceito, proposto por estudos no contexto norte-americano, pouco tem sido utilizado na literatura brasileira para entender as relações entre a diversidade de movimentos sociais que se apresentam hoje no país, sob diferentes orientações políticas. Segundo Silva (2020, p. 6),

a quase ausência do conceito e dos debates a ele relacionados se deve ao viés do campo de estudos de movimentos sociais no Brasil (...), que tende a negligenciar a análise dos processos de organização e mobilização contestatória de segmentos dominantes e/ou de segmentos conservadores/de direita a partir das teorias de movimentos sociais.

Portanto é preciso considerar que "o fenômeno de interações contínuas entre movimentos opostos exige uma revisão e extensão de nossas teorias de movimentos sociais e mudança social" (Meyer \& Staggenborg, 1996, p. 1629). Para Meyer \& Staggenborg (1996), a relação movimentos/contramovimentos faz parte de uma discussão contemporânea da política, que busca mostrar que qualquer movimento social que atue no campo de lutas pela transformação de significados gera opositores. De modo que examinar a "relação dinâmica entre movimentos e contramovimentos para conectar claramente a atividade do movimento à política e à opinião pública" (Banaszak \& Ondercin, 2010, p. 1) é fundamental. Além disso, as mudanças nas políticas públicas são resultados dessa interação, podendo assumir duas 
formas: "cada tipo de movimento pode reagir às ações do outro ou cada um pode reagir ao sucesso do outro" (Banaszak \& Ondercin, 2010, p. 6).

Mais do que a contraposição, os contramovimentos também podem objetivar - e geralmente objetivam - mudanças de cenários. Lo (1982), observou que muitos movimentos conservadores norte-americanos que reagiram aos movimentos pelos direitos civis e mulheres, por exemplo, buscavam incidir sobre as leis. Portanto não agem apenas reativamente, mas buscam implementar estratégias que permitam assegurar seus interesses de forma duradoura. Em se tratando de um "ativismo conservador" (Vaggione, 2005), a exemplo dos apoiadores do "Pacote de Veneno", Lo (1982) identificou que a força deles está não no apoio e aprovação popular, mas nas redes e ligações com governos e outras elites. Utilizamos a definição de Lo sobre os movimentos de direita como "movimentos sociais cujos objetivos declarados são de manter estruturas de poder, o status, a honra ou diferenças e valores sociais tradicionais" (Lo, 1982, p. 108).

De forma complementar, as concepções de campo político em Bourdieu (2011) contribuem como pano de fundo no entendimento dos processos de interação entre os diferentes agentes em disputa. Para Bourdieu (2011, p. 195), o campo político (...) é um microcosmo, isto é, um pequeno mundo social relativamente autônomo no interior de um grande mundo social. Nele se encontrará um grande número de propriedades, relações, ações e processos que se encontram no mundo global, mas esses processos, esses fenômenos, revestem-se aí de forma particular.

Entender o campo político onde esses agentes atuam torna-se relevante na medida em que possibilita apreender como as dinâmicas sociais funcionam e como os capitais são distribuídos. Conforme destaca Thiry-Cherques (2006, p. 39), ao fazer uma releitura dos conceitos de Bourdieu, "em todo campo a distribuição de capital é desigual, o que implica que os campos vivem em permanente conflito, com os indivíduos e grupos dominantes procurando defender seus privilégios em face do inconformismo dos demais indivíduos e grupos".

Igualmente as noções de ciclos de consagração e produção de crenças (Bourdieu, 2002) são mobilizadas para compreender como ideias e representações são construídas contra e a favor da flexibilização da legislação sobre agrotóxicos, mas que são também orientadoras de modelos de desenvolvimento rural e, consequentemente, de sociedade.

Os conceitos abordados aqui constituem chaves de leitura importantes que revelam as configurações dos enfrentamentos em torno da legislação dos agrotóxicos e desvendam dimensões mais amplas dessas lutas.

\section{3. $O$ modelo de desenvolvimento rural brasileiro e a formação do campo de disputas}

O aumento da utilização de agrotóxicos no Brasil está diretamente relacionado à modernização da agricultura, implementada a partir dos anos 1970, pelo governo militar sob o argumento de aumentar a oferta de alimentos a custos mais baixos (Graziano da Silva, 1982). O projeto se pautava numa concepção do meio rural como lugar do atraso, do rústico e do anti-moderno. A pobreza rural e os conflitos por terra eram consequência da carência de modernização (Rozendo, 2006) e a solução era, portanto, industrializar o campo. O modelo "pre- 
conizava o incentivo ao uso intensivo de insumos químicos (agrotóxicos e fertilizantes), biológicos (sementes melhoradas) e mecânicos (máquinas e implementos agrícolas) para a agricultura" (Franco \& Pelaez, 2016, p. 215).

A reestruturação dos serviços de assistência técnica e a criação de estruturas curriculares em cursos de ciências agrárias sob o enfoque da modernização funcionaram como "instâncias de socialização, produção e consagração cultural" (Bourdieu, 2002, p. 10) da nova proposta. Além disso, sua implementação contou com vultosos subsídios estatais. A modernização reconfigurou o meio rural, sob vários aspectos, estabelecendo uma nova relação sociedade/natureza (Rozendo, 2006), o que resultou em um ambiente cada vez mais artificializado e instituiu um modelo químico dependente.

Nos países do Norte, o modelo já enfrentava críticas, sobretudo com a publicação do livro: Primavera silenciosa, de Rachel Carson, no ano de 1962, que denunciava que sua adoção implicava em riscos ambientais e sociais em razão da utilização intensiva de agrotóxicos. Contudo o alerta não foi suficiente para orientar estilos mais sustentáveis de agricultura, mesmo considerando o contexto global de crise ambiental que apontava o esgotamento do modelo hegemônico de desenvolvimento.

No Brasil, na contraposição à modernização, estavam intelectuais pertencentes aos movimentos de agricultura alternativa (Brandenburg, 2002; Luzzi, 2008) e grupos religiosos ligados às Comunidades Eclesiais de Base da Igreja Católica que contribuíram fortemente para a difusão dos princípios agroecológicos (Souza, 2017), estimulando a criação de organizações sociopolíticas em várias regiões. Apesar dos esforços, as iniciativas ficaram à margem do modelo dominante, no qual o binômio latifúndio/monocultura foi consagrado política e socialmente como a forma legítima de desenvolvimento rural e agrícola (Wanderley, 2014).

Com a redemocratização do país, na década de 1980 , vieram à tona temas e atores anteriormente negligenciados e silenciados pelo regime ditatorial. A emergência de movimentos como o Movimento dos Trabalhadores Rurais Sem Terra (MST) e de agricultores familiares vai marcar a disputa pelo protagonismo do desenvolvimento rural, mas ainda orientado, em grande medida, pelo modelo hegemônico de agricultura. À medida que esses atores se consolidavam, inclusive por meio de articulações internacionais com a Via Campesina, questões ambientais e de segurança alimentar tornaram-se mais relevantes e, com elas, o problema do uso indiscriminado dos agrotóxicos. Isso foi bem evidente no caso do MST e sua guinada à agroecologia, a partir dos anos 2000 (De Carli, 2013) e nos segmentos da agricultura familiar mais identificados com o campesinato.

Apesar do grande impacto ambiental do projeto de modernização no campo, será somente em 1989 que se estabelece uma nova Lei de Agrotóxicos e Afins ( $\left.n^{\circ} 7.802\right)$, regulamentada, em 1990 e, novamente, em 2002 (Stopelli \& Magalhães, 2005) quando o governo passa a exigir das empresas, a responsabilidade na destinação das embalagens, novas formas de rotulagem e informação ao consumidor (MMA, 2000). Em 2001, adequando-se às recomendações internacionais do CODEX Alimentarius $^{2}$, a Agência Nacional de Vigilância Sanitária

${ }^{2}$ O Codex Alimentarius é um programa conjunto da Organização das Nações Unidas para Agricultura e Alimentação (FAO) e da Organização Mundial da Saúde (OMS), criado em 1963, com o objetivo de estabelecer normas internacionais na área de alimentos, incluindo padrões, di- 
(Anvisa) idealiza o Projeto de Acompanhamento de Resíduos dos Agrotóxicos (PARA) ${ }^{3}$ que, em 2003, torna-se Programa. Os resultados do Relatório PARA (2001 a 2007) apontaram altos níveis de resíduos nos produtos in natura:

O histórico das irregularidades [...] permite concluir que o maior problema [...] não está na forma de aplicação do produto na cultura além dos limites permitidos, mas sim no uso indiscriminado de agrotóxicos não autorizados para as culturas (ANVISA, 2008, p. 19).

No mesmo ano de divulgação desse relatório, o Brasil assumiu o primeiro lugar no ranking mundial de consumo de agrotóxico (ABRASCO, 2015). Contraditoriamente, isso correu em paralelo à criação de uma série de ações com foco na agroecologia e no contexto de uma ampla campanha pela soberania alimentar, tema central da plataforma política que elegeu Luiz Inácio Lula da Silva em 2002. Entre elas, destacam-se de 2003 a 2016: a reativação do Conselho Nacional de Segurança Alimentar e Nutricional (CONSEA); a criação da linha de fomento à agroecologia no âmbito do Programa Nacional de Fortalecimento da Agricultura Familiar (PRONAF); o Programa de AquisiçÏ grama Nacional de AlimentaçÏ̈ Escolar (PNAE); a
Política de 1 Milhão de Cisternas (P1MC); além do estabelecimento da Política Nacional de Segurança Alimentar e Nutricional e da Politica Nacional de Agroecologia e Produção Orgânica (PNAPO) etc (Canavesi et al, 2016; Diniz \& Rozendo, 2019). Essas ações geraram muitos confrontos dentro e fora do governo e acabaram fortalecendo o debate sobre a importância da agricultura familiar, segurança alimentar e da agroecologia na sociedade brasileira. Contudo, o governo continuou apoiando fortemente o agronegócio, como evidencia a nomeação de representantes do setor para o Ministério da Agricultura, Pecuária e Abastecimento bem como a destinação de vultosos aportes orçamentários de 2003 a $2016^{4}$.

Especialmente nos governos Lula, houve uma tentativa de "acomodar as forças políticas antagônicas em dois ministérios: [...] o Ministério da Agricultura, Pecuária e Abastecimento (MAPA), vinculado ao agronegócio; e o Ministério do Desenvolvimento Agrário (MDA)" (Porto, 2018, p. 3) responsável pela política de reforma agrária e pela promoção da agricultura familiar. Para o autor, foi o momento de um "contraditório pacto político" que buscava "comportar a política de alianças, garantir a governabilidade e dar continuidade ao superávite fiscal" (Porto, 2018, p. 3). Segundo Wolford

retrizes e guias sobre Boas Práticas e de Avaliação de Segurança e Eficácia. Seus principais objetivos são proteger a saúde dos consumidores e garantir práticas leais de comércio entre os países. "Embora as normas, diretrizes e recomendações adotadas pelo Codex não sejam vinculantes no contexto das legislações alimentares nacionais, os membros da Organização Mundial do Comércio (OMC) são incentivados a harmonizar suas legislações nacionais com as normas internacionais. Além disso, essas normas podem ser usadas como referência para a dissolução de controvérsias em disputas do comércio de alimentos (ANVISA, 2016).

${ }^{3}$ A Anvisa iniciou em 2001, o Projeto de Análise de Resíduos de Agrotóxicos em Alimentos (PARA), visando avaliar a qualidade dos alimentos em relação aos resíduos de agrotóxicos (ANVISA, 2008).

${ }^{4}$ A nomeação de Roberto Rodrigues (2003-2006), ligado à Associação Brasileira de Agronegócio (ABAG), para o Ministério da Agricultura, foi um dos primeiros sinais de uma tentativa de coalização política do governo Lula com a bancada ruralista. Os sucessores da pasta seguiram o mesmo perfil. 
\& Sauer (2018), Lula acreditava numa possível negociação entre o agronegócio e o campesinato. A estratégia de criar dois ministérios para tratar das questões do rural não impediram os constantes tensionamentos. Foram inúmeras as polêmicas e disputas durante todo o governo dado que se tratava de fazer convergir interesses historicamente irreconciliáveis.

A eleição de Dilma Rousseff, no ano de 2010, ocorre num cenário de agravamento dos problemas ambientais no país, consequência do arrefecimento de pautas como a reforma agrária, as questões indígenas e da reativação de projetos polêmicos como a construção das mega-hidrelétricas - Belo Monte, Complexo Madeira, Complexo Tapajós -; abertura de rodovias e hidrovias; ampliação da exploração de madeira e minérios; expansão da pecuária e das monoculturas da soja e da cana de açúcar e a reforma do Código Florestal. A relação do movimento social com o governo de Dilma Rousseff, particularmente do movimento socioambiental (ambientalistas, ribeirinhos, indígenas, extrativistas, povos tradicionais), foi tensa. Na essência, a crítica dessa parcela do movimento residia no fato de que o governo optou por um modelo que privilegiava matrizes energéticas centralizadoras e poluidoras (fósseis), perigosas (nuclear) ou devastadoras do meio ambiente (hidrelétricas), com enormes investimentos. Isso, na opinião dos movimentos, foi responsável pela superexploração dos recursos naturais. É na esteira desses acontecimentos, de sucessivas vitórias de pautas dos setores empresariais e do agronegó- cio, que o debate sobre o uso dos agrotóxicos vai assumir relevância ${ }^{5}$.

A proposição do novo Código Florestal mostrou o potencial da "bancada ruralista" nesse período, conforme mostra Carneiro et al. (2012, p. 8): "No processo de aprovação do recente Código Florestal ficou evidente a aliança do poder federal com o setor agrário" a partir da qual se produziu uma série de narrativas enfatizando os benefícios da proposta. O discurso se centrava na "prosperidade econômica" do país e afirmava que "o código vigente penalizava os 'pequenos agricultores' com a criminalização pela ocupação de áreas de preservação permanente e da não averbação das áreas de reservas legais" (Carneiro et al., 2012, p. 101).

A "bancada ruralista" buscou, constantemente, construir uma narrativa que ocultasse as diferenças entre agronegócio e agricultura familiar, referindo-se em seus pronunciamentos a uma categoria genérica de "produtores rurais" com o claro propósito de apropriar-se de questões que incidiam, particularmente, sobre as pequenas propriedades. O movimento oscilava entre denegar a ação dos defensores da agricultura familiar ou usar suas pautas para "pegar carona" na boa reputação que o segmento desfrutava na opinião pública, por meio de um mimetismo político oportunista. Nas palavras de Bourdieu (2002), uma estratégia de "alquimia social" que transmuta o interesse do indivíduo ou de uma classe em interesse coletivo.

As disputas envolvendo o novo Código Florestal e a proposição de uma nova legislação de agro-

\footnotetext{
${ }^{5}$ Destaque-se que, desde o começo do debate sobre a flexibilização do Código Florestal, o governo de Dilma Rousseff nunca se colocou frontalmente contra as alterações da legislação e passou a adotar a postura de negociador, colocando-se como o tertius entre o agronegócio e o movimento social. A postura frouxa do governo não deveu-se apenas ao fato de que o tema dividia a sua base de apoio política, mas sobretudo ao seu modelo desenvolvimentista, no qual a questão ambiental nunca fora determinante. Apesar da intensa retórica, no modelo desenvolvimentista, a temática ambiental ficou subordinada à agenda econômica.
} 
tóxicos, que a partir de 2010 ocupam a centralidade do debate entre movimento e contramovimento, são objetivações de um projeto político, econômico, social que pretendia estruturar uma forma de percepção dos sujeitos (Bourdieu, 2002) sobre o destino do espaço rural, fortemente referenciadas no modelo do agronegócio.

As declarações da então Senadora Kátia Abreu (TV Senado, 2010), durante uma audiência pública que discutia os mecanismos de controle de agrotóxico ganharam grande repercussão. Ela afirmou que "os pobres tinham que comer produtos com agrotóxicos sim", pois era a única forma de se garantir acesso mais barato aos alimentos. Em sua fala, questionava as declarações do diretor da Anvisa, Agenor Álvares, ao jornal Le Monde Diplomatique, em que este mencionava a necessidade de maior controle por parte do órgão e a reavaliação de 14 agrotóxicos. Para ele, o Brasil está passando por um momento de transição no controle e na regulamentação do uso de agrotóxicos: "Nós interditamos a linha de produção na BASF, na Bayer e na Syngenta, que são as três maiores do mundo", afirma. É uma mudança de postura que obviamente não agrada a todos. A senadora rebateu as declarações perguntando o que “este cidadão tem contra o país?", e propunha que este fosse convocado juntamente com o Ministro da Saúde para prestarem esclarecimentos à comissão do Senado, alegando irresponsabilidade no exercício da função pública.

Estou trabalhando nessa matéria (da liberação dos agrotóxicos) desde 2002 Sr. Presidente e continuam os mesmos problemas [...] Não é possível que a Anvisa exerça um papel de atraso para o país dando prejuízo a agricultura [...] um setor responsável por $1 / 3$ do PIB, $1 / 3$ dos empregos e $42 \%$ das exportações (TV senado, 2010).
A narrativa procurava, por um lado, destacar as benesses econômicas do agronegócio e, ao mesmo tempo, descredibilizar entidades, estudos, grupos ou pessoas que questionassem a atuação do setor. Nessa ocasião, o IBGE também foi atacado pela senadora em razão dos resultados do Censo Agropecuário de 2006 (divulgados apenas em 2010) revelarem o protagonismo da agricultura familiar na produção de alimentos e o aumento da concentração de terra no país. Para ela, a coleta de dados tinha "inconsistências" que precisam ser revistas. Mitidiero et al. (2017) afirmam que o objetivo da senadora era desqualificar o trabalho do órgão, uma vez que os resultados contrariavam as narrativas do setor sobre quem realmente produzia alimento no país. Anvisa, IBGE, Ibama e os ministros das pastas de Meio Ambiente e Desenvolvimento Agrário foram alvos de ataques e críticas sistemáticas por parte dos representantes da bancada ruralista.

Nesse processo de "construção de verdades" sobre o agronegócio, é lançado, em 2011, o movimento "Sou Agro", com o propósito de construir uma imagem positiva do setor afastando-o da relação com a destruição de florestas. Conforme declarou o ex-ministro da agricultura Roberto Rodrigues no jornal Notícias Agrícolas (2011): "Trata-se de um movimento inédito. Nunca antes todos os setores se uniram e trabalharam de forma coordenada na promoção de sua imagem de forma estruturada e sinérgica". A campanha teve lugar nos principais veículos de comunicação do país com a presença de renomados atores e contou com "peças publicitárias em emissoras de tevê e rádio, revistas, internet, cinema e mídia eletrônica em elevadores. Foram seis filmes de tevê e cinema e 12 spots de rádio", numa verdadeira ofensiva simbólica que procurava por diversos meios ampliar a legitimidade 
do setor frente à opinião pública ${ }^{6}$. Segundo Bruno (2015, p. 6 e 7):

A construção da imagem do agro (...) busca ampliar indefinidamente a concepção de agro a todos os agentes e processos sociais da sociedade (...). Sou Agro simboliza, então, o princípio da universalização. 'Todos são agro, e se ainda não o são, deveriam sê-lo', dizem seus porta-vozes.

Ainda como parte dessa estratégia, a CNA financiou uma escola de samba do Rio de Janeiro. A manchete do Jornal Estadão anunciava: "Enredo da Mocidade Independente, em 2011, prega convivência entre o agronegócio e o meio-ambiente" e continua: o enredo "A parábola do divino semeador", [...] é uma das armas da CNA para se contrapor à campanha "Exterminadores do Futuro", com a qual os ambientalistas demonizam o agronegócio" (ESTADÃO, 2010). Para a CNA, essa era oportunidade de a Confederação mostrar a mais de 200 países "o papel da verdadeira agricultura" anunciava o site da instituição. Na continuidade dessa estratégia, em 2012, a CNA anuncia a campanha "Time Agro Brasil" tendo o jogador Pelé como seu garoto propaganda: "O vídeo, [...] associa o "campo" de futebol ao "campo" brasileiro, com seu potencial de produção de alimentos [...]." Com o slogan "Time Agro Brasil", a campanha pretende mudar a visão da sociedade sobre a agricultura brasileira, de acordo com a presidente da CNA, senadora Kátia Abreu (Canal Rural, 2012). Sob a ideia de "time", procuravam transmitir uma imagem de união entre diferentes segmentos do mundo rural em torno dos mesmos objetivos.

Essas ações são representativas do poder simbólico do agronegócio que procurava amalgamar seus propósitos às manifestações culturais brasileiras, mundialmente reconhecidas: o carnaval e o futebol num "verdadeiro ciclo de consagração que pretendia realizar a operação fundamental de alquimia social transformando relações arbitrárias em legítima" (Bourdieu, 2002, p. 211), a sua visão de mundo, em visão de todos. Para Bourdieu (1989, p. 14), o poder simbólico é um "[...] poder quase mágico que permite obter o equivalente que é obtido pela força (física ou econômica), graças ao efeito específico de mobilização, só se exerce se for reconhecido, quer dizer, ignorado como arbitrário".

Em 2011, sob o efeito das denúncias da $\mathrm{ABRASCO}^{7}$, sintetizadas no documento - Um alerta sobre os impactos dos Agrotóxicos na Saúde - que apontavam o aumento do número de agrotóxicos utilizados no país, organiza-se a "Campanha Permanente Contra os Agrotóxicos e pela Vida". Fruto da intensa articulação entre movimentos sociais do campo, organizações de apoio à agroecologia, sindicatos e entidades públicas de pesquisa, especialmente na área da saúde, o movimento reúne atualmente, mais de 150 organizações sociais entre elas: Articulação Nacional de Agroecologia (ANA), Associação Brasileira de Agroecologia (ABA), Consulta Popular, a Central Única dos Trabalhadores (CUT), Fase, a Fundação Oswaldo Cruz (Fiocruz/GT Agrotóxicos), Instituto Nacional

\footnotetext{
${ }^{6}$ Não foi apenas por estes meios que o setor do agronegócio procurou se consagrar como o "verdadeiro" protagonista do desenvolvimento rural. Lerrer (2020) mostra, em seu artigo como a revista Agroanalysis constituiu um instrumento potente na formação das representações dos atores do agronegócio em diversos temas. A própria consagração do termo agronegócio é atribuída pela autora aos conteúdos publicados na revista com a chancela da Fundação Getúlio Vargas.
}

${ }^{7}$ Disponível em: https://www.Abrasco.org.br/UserFiles/File/ABRASCODIVULGA/2012/DossieAGT.pdf acesso em 29/09/2020. 
do Câncer (INCA), Movimento dos Trabalhadores Rurais Sem Terra (MST), Movimento dos Pequenos Agricultores (MPA), Via Campesina, Movimento de Atingidos por Barragens (MAB), Terra de Direitos, além de parceiros internacionais, conforme site da campanha.

Na publicização dos estudos acadêmicos que apontavam a gravidade da situação brasileira em relação à utilização dos agrotóxicos, a "Campanha" buscava enfatizar a quantidade per capita de veneno consumida anualmente (sete litros) e suas consequências para a saúde. Também nesse caso, a construção dos repertórios discursivos passava pelo uso da ciência, da mobilização de diferentes recursos imagéticos e do lobby político. Foi lançando mão dessas estratégias que os representantes da "Campanha" buscaram sensibilizar as pessoas e agregá-las à luta.

Segundo uma das coordenadoras do movimento:

Queremos alertar a sociedade sobre a situação calamitosa no campo com o uso completamente abusivo dos agrotóxicos no cultivo. (...) Mas o grande problema de saúde pública tem sido o aumento do câncer (...). O que está diretamente ligado à alimentação com volumes absurdos de agrotóxicos (ECODEBATE, 2012).

A nomeação da Senadora Kátia Abreu, no ano de 2014, para o Ministério da Agricultura foi a consequência política vitoriosa do projeto do agronegócio. Denominada de "Miss desmatamento" e "Rainha da Motosserra" pelo Greenpeace e outros movimentos de defesa do meio ambiente, ela havia sido uma das principais defensoras do novo Código Florestal e da nova lei dos agrotóxicos, o PL 6.299/2002, além de ferrenha opositora aos movimentos sociais. À época em que presidiu a CNA, chegou a protocolar no Ministério da Justiça um documento pedindo ações duras para reprimir as ações organizadas pelo Movimento dos Trabalhadores Rurais Sem Terra (MST).

Além disso, no ano de 2015, a então ministra ameaçou criar um órgão próprio para a liberação dos agrotóxicos, já que a Anvisa, em seu entendimento, vinha dificultando a vida do setor do agronegócio, pela grande burocracia que retardava a liberação dos registros (G1, 2015). Além disso, a ministra esteve à frente das articulações que barraram o andamento do Programa Nacional de Redução de Agrotóxico (Pronara), construído no âmbito da Comissão Nacional de Agroecologia e Produção Orgânica (CNAPO).

Em 2016, logo após a Câmara dos Deputados ter votado a admissibilidade do impeachment da presidente Dilma Rousseff, a bancada ruralista apresentou, ao vice- presidente Michel Temer, a chamada "Pauta Positiva" (Agência FPA, 2016) na qual foram elencadas as medidas para "alavancar o agronegócio no Brasil" como: Projetos de Leis prioritários, envolvendo reformas na legislação trabalhista, na regularização fundiária, novo marco regulatório para agrotóxicos, a anistia de dívidas do setor do agronegócio, incremento de subsídios à produção etc.

As tensões entre movimento e contramovimento se recrudesceram com o impeachment de Dilma Rousseff, em 2016, especialmente pela priorização dada pelo então presidente Michel Temer ao agronegócio. Se nos governos de Lula e Dilma houve uma tentativa de acomodação dos interesses do agronegócio e dos representantes da agricultura familiar e defensores da reforma agrária, no novo governo, há um claro posicionamento em desfavor 
desses últimos. Ao assumir o cargo, Temer desmantelou rapidamente todas as políticas de agricultura familiar. "O MDA foi dissolvido e seus programas foram transferidos para o Ministério do Desenvolvimento Social e Agrário (MDSA)" (Sabourin et al., 2020, p. 9) enquanto a "Pauta Positiva", proposta pela bancada ruralista, foi impulsionada. $\mathrm{O}$ reposicionamento do agronegócio mediante a ofensiva conservadora no país acirrou a disputa em torno das narrativas sobre o uso dos agrotóxicos.

Do lado do movimento dos que apoiam o "Pacote do Veneno", segue a aposta em campanhas publicitárias, como a veiculada no horário nobre da TV Globo, desde o ano de 2016, com o slogan: "Agro é tech, agro é pop, agro é tudo". O agronegócio aparece como símbolo do progresso científico e tecnológico, da precisão e da excelência, do qual todos se beneficiam, daí ele ser "tech, pop e tudo"8. Na sequência desse projeto, em 2018 , quando seria votado o PL 6.299.02, a CNA contratou o publicitário Nizan Guanaes ${ }^{9}$ para criar uma campanha que melhorasse a imagem do setor. Em uma campanha, atribuída a ele, as falas de artistas alertando para problema da aprovação do "Pacote do Veneno" eram rebatidas e descaracterizadas com novas informações. Os depoimentos aparecem sendo carimbados com a expressão fake news, em vermelho.

O grande reforço da campanha do lado do lobby político é a atual Ministra da Agricultura,
Tereza Cristina (DEM). Em 2016, ainda como deputada federal e líder da bancada ruralista, ela foi a principal articuladora do movimento que acelerou a tramitação do PL 6.299/02 que estava praticamente parada ${ }^{10}$. De autoria do ex-ministro da agricultura, Blairo Maggi, o projeto original corre na Câmara dos Deputados há 16 anos e "reuniu diversos outros $\mathrm{PLs}^{11}$ que se encontravam tramitando no Congresso Nacional desde 1999 até 2017" (Porto, 2018, p. 1). $\mathrm{O}$ apensamento desses outros PLs, sobretudo o 3200/ 2015, proposto pelo deputado Covatti Filho, é o que representa as mudanças mais significativas da legislação atual. O que se está denominando de PL do veneno na realidade é o conjunto desses PLs, representados pelo PL 6.299/02. Pelo protagonismo na articulação que garantiu o andamento desse projeto, os colegas de Tereza Cristina lhe deram o codinome de "Musa do veneno" (Repórter Brasil, 2018). Sinteticamente as principais modificações propostas pelo chamado "Pacote do Veneno" envolvem: 1) Mudanças sobre a competência nos processos de decisão sobre a liberação ou não de agrotóxicos restringindo o papel dos Ministérios da Saúde, do Meio Ambiente e atribuindo ao Ministério da Agricultura a decisão final; 2) Mudança de nomenclatura de "Agrotóxicos" para produtos fitossanitários e ou pesticidas; 3) Mudanças nos critérios de avaliação dos Riscos - Rebaixamento da Toxicidade de Produtos, com maior número

\footnotetext{
${ }^{8}$ A campanha foi lançada pela Rede Globo e, segundo o diretor de marketing da emissora, Roberto Schmidt, tinha como objetivo "conectar o consumidor com o produtor rural e ao mesmo tempo desmistificar a produção agrícola aos olhos da sociedade urbana” (Startagro, 2017).

${ }^{9}$ Em 2017, o empresário declarou no Fórum de Agronegócios da EXAME que: “o agronegócio brasileiro é muito bom em termos de produtividade e gestão", mas ainda deixa a desejar no momento de se promover. Ele afirmou ainda que o Estado deveria favorecer mais o setor, que é de suma importância para a economia brasileira (Exame, 2017).

${ }^{10}$ Um exame da ficha de tramitação do PL mostra que em 2016 houve 23 ações legislativas, enquanto estas não passaram de quatro em anos anteriores, inclusive sem qualquer registro de 2007 a 2011 (Câmara dos Deputados, 2020).

${ }^{11}$ Outros PLs como 1687/2015 que propõe a "Política Nacional de Apoio aos Agrotóxicos e Afins de Baixa Periculosidade" e o PL $3200 / 2015$ que dispõe sobre a Política Nacional de Defensivos Fitossanitários e de Produtos de Controle Ambiental seus Componentes e Afins.
} 
de produtos passando para "limites aceitáveis"; e 4) Alteração dos Prazos para liberação de novos produtos: deve ser definida entre 30 dias e dois anos, de acordo com o tipo de produto. "Caso os cronogramas não sejam cumpridos, os fabricantes podem solicitar uma autorização temporária para comercializar seus produtos até que a análise seja concluída" (UOL, 2018). Cada um dos pontos elencados aqui foram objeto de intenso debate e mobilizações envolvendo audiências públicas com especialistas contra e a favor do PL.

Em 2018, com a eleição de representantes do legislativo de orientação conservadora, a "Pauta Positiva" ganhou força, em especial a proposição de alteração da legislação de agrotóxicos, amplamente apoiada pelo presidente eleito, Jair Bolsonaro, que havia falado abertamente ao jornal Estadão: "esse Governo é de vocês", referindo-se à "bancada ruralista".

Em 2016, como forma de se contrapor aos avanços do "PL do Veneno", a ABRASCO propõe a Política Nacional de Redução de Agrotóxicos - PNARA - por intermédio do Projeto de Lei 6670/2016. Conforme site de notícias da Câmara, a ideia da proposta era:

Implementar ações que contribuam para a redução progressiva do uso de agrotóxicos na produção agrícola, pecuária, extrativista e nas práticas de manejo dos recursos naturais, com ampliação da oferta de insumos de origens biológicas e naturais, contribuindo para a promoção da saúde e sustentabilidade ambiental, com a produção de alimentos saudáveis.

A proposição que tramitou em paralelo ao "PL do Veneno" originou-se do Programa Nacional de Redução de Agrotóxico (Pronara), construído no âmbito da Comissão Nacional de Agroecologia e Produção Orgânica (CNAPO). O programa, que serviria como instrumento de incentivo à produção agroecológica, foi barrado pelo Ministério da Agricultura, à época dirigido por Kátia Abreu, conforme mencionado anteriormente. As organizações da sociedade civil reunidas em torno da plataforma \#ChegaDeAgrotóxicos transformaram o programa em projeto de lei, apresentado à Comissão de Legislação Participativa. A luta contra os agrotóxicos também ganhou o reforço, em 2017 com a publicação do trabalho da pesquisadora Larissa Bombardi, que lançou em Berlim o documento: Geografia do uso de agrotóxicos no Brasil e conexões com a União Europeia, denunciando a contaminação dos alimentos (Jornal da USP, 2019).

\begin{abstract}
Apesar dos esforços da "Campanha" e da proposição do PNARA, o PL 6.299/2002 foi aprovado. "Mesmo com fortes pressões públicas contrárias, inclusive de inúmeras figuras públicas e artistas, em 25 de junho de 2018 a Comissão Especial deliberou em sessão tumultuada pela aprovação por ampla maioria do parecer do relator, o Deputado Luiz Nishimori (PR-PR)" (Porto, 2018, p. 1 e 3).
\end{abstract}

A atual Ministra da Agricultura, Tereza Cristina, em entrevista para imprensa, após aprovação do projeto na comissão afirmou: "Nós ganhamos a batalha, mas ainda temos uma guerra". Ela defendeu a liberação dos agrotóxicos e ainda buscou tranquilizar os consumidores: "nenhum consumidor está sendo impactado (...) Não podemos aterrorizar os consumidores brasileiros, muito menos os consumidores externos, dos mais de 162 países que importam a produção brasileira" (Folha de São Paulo, 2019). A ministra também declarou que 
“não colocamos veneno no prato de ninguém", em referência ao símbolo de uma caveira num prato de comida com o slogan “Agrotóxico Mata” usado pela "Campanha contra os Agrotóxicos e Pela Vida" que busca sensibilizar a população ressaltando o perigo presente no dia a dia do brasileiro. Valendo-se dessa mesma referência, em 2017, a Revista Problemas Brasileiros publicou uma matéria com o título: $\mathrm{O}$ Veneno no Prato (ABRASCO, 2017). A ministra ainda:

Convocou representantes do agronegócio brasileiro a "ganhar a guerra da comunicação". "Precisamos ganhar a guerra da comunicação e o agronegócio precisa se unir. É inadmissível que o agro tenha sido bombardeado pela mídia nacional falando que nosso alimento é inseguro, isso é uma inverdade", declarou a ministra, durante o Congresso Brasileiro do Agronegócio, promovido pela Associação Brasileira do Agronegócio (Abag) em São Paulo" (Exame, 2019).

Em consonância com o posicionamento da ministra, o deputado Domingos Sávio (PSDB-MG), argumentou: "O que a produção brasileira faria sem os defensivos agrícolas, tanto na medicina veterinária como na agronomia (...) É impossível. Não tem nenhuma atividade produtiva que dê essa margem de lucro para produzir sem usar nenhum defensivo" (Câmara dos deputados, 2019).

Do lado do contramovimento, essa retórica dos lucros econômicos vem sendo fortemente questionada. Soares \& Porto (2012), em um estudo realizado no estado do Paraná, mostram que os custos sociais com a utilização de agrotóxicos, podem variar entre US\$ 11 e 89 milhões considerando apenas os gastos com o tratamento de casos de intoxicação aguda. Além disso, a lucratividade se faz mediante forte subvenção estatal. Levantamento realizado pela Repórter Brasil e a Agência Pública mostra que, nos últimos 14 anos, o BNDES (Banco Nacional de Desenvolvimento Econômico e Social) emprestou R\$ 358,3 milhões a empresas do setor (UOL, 2020). Enquanto os lucros da atividade, obtidos mediante o apoio estatal, são apropriados individualmente, os custos sociais e ambientais são divididos com toda a sociedade. Também a narrativa da necessidade de uso de agrotóxicos para ampliar a produção de alimentos vem sendo colocada em xeque uma vez que 79\% dos agrotóxicos são usados em apenas quatro produtos: soja, milho, algodão e cana de açúcar. Segundo o economista Cechi, da UnB, em entrevista para o portal do Uol:

O agrotóxico é utilizado principalmente em culturas que não são alimentos, ou seja, commodities cujos preços são estabelecidos pelo mercado internacional. Não são os produtores que escolhem o preço. Em 2015 , as plantações de soja foram o destino de $52 \%$ da venda de todos os agrotóxicos do Brasil. Milho e cana-de-açúcar aparecem em segundo lugar, com 10\% cada, seguidos do algodão, com $7 \%$, segundo dados do Sindiveg (UOL, 2020).

Ou seja, o argumento de que a utilização dos agrotóxicos garante a oferta de alimentos a menores custos para o consumidor é no mínimo, controverso, principalmente quando se considera os gastos em função dos agravos à saúde, como reitera Soares \& Porto (2012), e a contaminação ambiental, conforme revela Dossiê da ABRASCO (2015).

Apesar das inúmeras controvérsias, os projetos do "Pacote do Veneno" e do PNARA estão prontos para apreciação pelo Plenário da Câmara, mas ambos "parados" até o momento. "Parados" porque desde 2019, mesmo sem aprovação do PL, houve 653 novos registros de agrotóxicos no Brasil, 
sendo 150 apenas em 2020 (118 só durante o isolamento social ocorrido em razão da pandemia do coronavírus), 44\% destes banidos na União Européia, conforme afirma representante do movimento da Campanha Permanente Contra os Agrotóxicos.

O grupo lançou, em Abril de 2020, o relatório "Agrotóxicos Perigosos. Bayer e BASF - um negócio global com dois pesos e duas medidas". A publicação foi uma ação da Campanha juntamente com a rede INKOTA, a Fundação Rosa Luxemburgo, a MISEREOR e a organização sul-africana Khanyisa. Com a manchete: "Banidos na Europa e bem-vindos no Brasil: o novo estudo apresenta as incoerências no comércio de agrotóxicos" e busca sensibilizar também a comunidade internacional. $\mathrm{Na}$ live de lançamento da publicação, os participantes alertaram para o problema do rebaixamento do grau de toxicidade dos agrotóxicos pela Anvisa:

Assim, mais de 500 dos 800 produtos agrotóxicos hoje considerados altamente tóxicos vão passar para as classes menos perigosas, o que deve aumentar a produção e o consumo desse tipo de pesticida. Além disso, eles terão menos alertas no rótulo, ou seja, perdem a tarja vermelha e a caveira que chamava atenção sobre o risco mesmo para agricultores de baixa escolaridade (CAMPANHA CONTRA OS AGROTÓXICOS E PELA VIDA, 2020).

Para os membros da Campanha, o que está ocorrendo é a "violação dos direitos que se faz de forma coordenada privilegiando: latifúndio, grilagem e agrotóxico" (Live "Agrotóxicos Perigosos"Agrotóxicos Perigosos: Bayer e BASF, um negócio global com dois pesos e duas medidas $(2020)^{12}$. A marcha do veneno continua e a desoneração fiscal, concedida pelo governo federal, extensiva a estados e municípios, denominada de "bolsa agrotóxico", é um dos exemplos disso. No ano de 2016, o Partido da Solidariedade com apoio do: Instituto Brasileiro de Defesa do Consumidor (Idec), Associação Brasileira de Saúde Coletiva (Abrasco), Defensoria Pública do Estado de São Paulo, Associação Brasileira de Agroecologia (ABA), Campanha Permanente contra os Agrotóxicos e pela Vida e a ONG Terra de Direitos entrou com uma Ação Direta de Inconstitucionalidade (ADI 553), questionando a referida concessão. A ADI já havia recebido parecer favorável da Procuradoria Geral da República e foi encaminhada ao STF. Assim, em fevereiro de 2020, a ABRASCO lançou o relatório "Uma política de Incentivo fiscal a agrotóxicos no Brasil é injustificável e insustentável" com o propósito de subsidiar a decisão do Supremo (Frente Parlamentar Ambientalista, 2020) $)^{13}$. A ação "questiona a lógica de considerar os agrotóxicos como itens fundamentais para o desenvolvimento do país. Ela compara os venenos a categorias como a de cigarros, considerados perigosos à saúde" que em razão de seus custos sociais, arcados pela população, "recebem taxação extra e não descontos nos impostos" (Brasil de Fato, 2020).

Segundo o relatório:

O total de benefícios fiscais concedidos aos agrotóxicos em 2017 se aproxima de R $\$ 10$ bilhões, sendo que o tributo responsável pelo maior montante desonerado

\footnotetext{
${ }^{12}$ Disponível em https://www.youtube.com/watch?v=wbW9mVmgPIY acesso em 28/04/2020.

${ }^{13}$ A ação pede a inconstitucionalidade do Decreto 7.660/2011, que libera 24 substâncias do pagamento do Imposto sobre Produtos Industrializados (IPI), e de dois trechos do Convênio n ${ }^{\circ}$ 100/97, do Conselho Nacional de Política Fazendária (Confaz). O STF postergou a votação, marcada para 19/02/2020 e até o momento da escrita deste artigo não havia retomado a pauta (Frente Parlamentar Ambientalista, 2020).
} 
foi o ICMS, com $63,1 \%$ do total; seguido do IPI, com $16,5 \%$; das contribuições sociais Pis/Pasep e Cofins, com $15,6 \%$ e; por último e com o menor montante, o imposto de importação, com $4,8 \%$. O total desses benefícios representa quase quatro vezes a verba do Ministério do Meio Ambiente, como aponta matéria produzida pelas agências Repórter Brasil e Pública (ABRASCO, 2020).

Do lado do movimento, uma das estratégias da disputa foi o enfraquecimento de vários espaços de controle social como forma de silenciamento e apagamento dos movimentos de contraposição. Exemplo disso foi a extinção do Conselho Nacional de Segurança Alimentar (CONSEA), no primeiro ato presidencial do governo de Bolsonaro. O órgão teve um papel fundamental na luta por Segurança Alimentar e Nutricional e pelo Direito Humano à Alimentação, responsável por congregar representantes de vários segmentos que orientaram as estratégias que retiraram o Brasil do mapa da fome.

Segundo a representante da INKOTA, o relatório "Agrotóxicos Perigosos. Bayer e BASF - um negócio global com dois pesos e duas medidas" foi lançado também na Alemanha, sede das duas maiores indústrias de agrotóxicos do mundo: a Bayer e a Basf, com o propósito de sensibilizar a população local e os seus acionistas para o problema da comercialização. A Alemanha ocupa atualmente a segunda posição no ranking mundial de exportação de agrotóxicos, embora internamente, o país apoie fortemente a produção orgânica. $\mathrm{O}$ referido documento pretendia constranger o governo brasileiro com a denúncia internacional.

\section{Considerações finais}

Analisou-se a relação movimento e contramovimento em torno da utilização dos agrotóxicos a partir do debate entre os defensores do chamado "Pacote do Veneno" e os apoiadores da "Campanha Permanente de Luta Contra os Agrotóxicos e Pela Vida", consubstanciadas nos PLs 6299/02 e 6670/2016. Foi identificado, conforme sugere Lo (1982), seus processos de interação, sua capacidade de incidir dentro e fora do governo, propondo leis, procurando ganhar adesão da opinião pública por meio de inúmeros recursos discursivos e imagéticos. Nesse processo, a chancela da ciência e o lobby político também constituíram importantes formas de mobilização de transformação de significados. Verificou-se como esses movimentos reagem à ação do outro (Banaszak \& Ondercind, 2010) e apresentam demandas concorrentes ao Estado (no caso, um PL que flexibiliza a legislação de agrotóxicos e outro que restringe) bem como reverberações nas estruturas estatais, ao que Banaszak (2005) chama de "ativismo institucional". Observou-se que formas de ativismo institucional tanto de direita quanto de esquerda estiveram presentes nos governos pós-abertura democrática, mas de modo bastante assimétrico. Mesmo durante os governos identificados como mais progressistas (2003 a 2016), as pautas do agronegócio foram amplamente privilegiadas, tanto em termos de recursos destinados ao setor quanto pelas políticas que conseguiram implementar, novo Código Florestal, manutenção da desoneração de impostos sobre comercialização de agrotóxicos, além do processo crescente de desregulamentação da política de agrotóxico.

A partir de 2016, verificou-se a predominância de um ativismo institucional de cunho conservador com o fortalecimento das pautas da bancada ruralista e de sua Agenda Positiva ao mesmo tempo que 
processava o desmantelamento de diversas políticas orientadas à agricultura familiar, reforma agrária, agroecologia e segurança alimentar. Apesar das assimetrias nas cotas de poder entre os grupos, os enfrentamentos continuam e, recentemente, a "Campanha Permanente de luta contra os agrotóxicos e pela vida" tem se mobilizado internacionalmente, apoiando também uma série de iniciativas municipais e estaduais que limitam o uso de agrotóxicos. Vale destacar aqui as mobilizações que resultaram nas restrições da pulverização aérea no estado do Ceará e a Lei de Florianópolis que baniu o uso de agrotóxico na parte insular do município.

No processo analisado aqui, identificou-se que tanto o movimento como o contramovimento lançam mão de repertórios discursivos que procuram construir esquemas perceptivos que favoreçam a sua luta. Há uma escolha planejada do que narrar, excluindo e/ou alterando informações sobre as consequências do uso dos agrotóxicos no país revelando tensões, conflitos, rupturas, conformando um campo político extremamente interessante de análise para a teoria social. Compreende-se que os embates em torno da pauta dos agrotóxicos fazem parte de um quadro maior de divergências envolvendo a defesa de distintos modelos de desenvolvimento, mas principalmente, a luta por diferentes projetos societários. Até agora nessa "guerra", como se referiu a ministra Tereza Cristina, os interesses econômicos do setor do agronegócio parecem ter prevalecido sobre os interesses sociais e de saúde da população brasileira. Recentemente, os sucessivos desastres ambientais no Brasil, como o desmatamento na Amazônia (objeto de artigo da revista Science), os incêndios do Cerrado e Pantanal que ganharam grande repercussão internacional estão colocando o agronegócio na mira de inúmeras críticas, inclu- sive com ameaças de encerrar contratos comerciais importantes. Esse movimento tem produzido fissuras na coalizão política do setor, como revelou recentemente a saída da Associação dos Produtores de Soja da Associação Brasileira do Agronegócio. Segundo um dos representantes da APROSOJA: "Tentamos várias vezes com a diretoria que olhasse para o Brasil que produz e protege. (....). Somos os que mais protegem e eles conseguiram (a ABAG), sendo uma associação que se diz representante do agronegócio brasileiro, levar a uma imagem totalmente distorcida" (ISTO É, 2020). Quiçá essas rupturas e pressões sociais e comerciais abram espaços para reposicionamentos capazes de dar respostas na dimensão e altura que a atual crise ambiental carece.

\section{Agradecimentos}

Os autores agradecem a leitura atenta e as considerações do Prof. Dr. Cesar Sanson (UFRN) e da Profa. Dra. Angela Damasceno (UFPR), além dos pareceristas anônimos da revista. Uma das autoras, em especial, agradece a possibilidade de discutir os conceitos de movimento/contramovimento com o Prof. Dr. Marcelo Kunrath Silva (UFRGS) no período da licença capacitação (jan-abr/2020). Também agradecemos à Capes a concessão de bolsa ao terceiro autor, cujo debate do tema da dissertação despertou nosso interesse em realizar esse artigo.

\section{Referências}

Abers, R. N.; Serafim, L.; Tatagiba, L. Repertórios de Interação Estado-Sociedade em um Estado Heterogêneo: 
A Experiência na Era Lula. DADOS - Revista de Ciências Sociais, 57(2), 325-357, 2014.

ABRASCO - Associação Brasileira de Saúde Coletiva. Dossiê ABRASCO. Um alerta sobre os impactos dos Agrotóxicos na Saúde. Rio de Janeiro: World Nutrition - Rio, 2012.

ABRASCO - Associação Brasileira de Saúde Coletiva. Um alerta sobre os impactos dos Agrotóxicos na Saúde. Rio de Janeiro/São Paulo, Escola Politécnica de Saúde Joaquim Venâncio: Expressão Popular, 2015.

ABRASCO - Associação Brasileira de Saúde Coletiva. Revista Problemas Brasileiros fala sobre o 'Veneno no prato', 2017. Disponível em: <https://www.Abrasco.org. $\mathrm{br} /$ site/noticias/movimentos-sociais/revista-problemas-brasileiros-fala-sobre-o-veneno-no-prato/27842/>. Acesso em: out. 2020.

ABRASCO - Associação Brasileira de Saúde Coletiva. Insustentável peso da isenção fiscal a agrotóxicos, 2020. Disponível em <https://www.Abrasco.org.br/site/noticias/ institucional/Abrasco-mostra-isencao-fiscal-a-agrotoxicos-e-insustentavel/45223/>. Acesso em: out. 2020.

Agência FPA. Presidente do FPA divulga pauta positiva 2016/2017 em reunião de secretários de estado da agricultura, 2016. Disponível em: https://agencia.fpagropecuaria. org.br/2016/05/03/presidente-da-fpa-divulga-pauta-positiva-20162017-em-reuniao-de-secretarios-de-estado-da-agricultura/. Acesso em: abr. 2020.

Anvisa - Agência Nacional de Vigilância Sanitária. Programa de análise de resíduos de agrotóxicos em alimentos (PARA). Relatório de Atividades 2001-2007. Brasília, 2008. Disponível em: <http://portal.Anvisa.gov.br/documents/111215/117818/relatorio\%2B2001\%2B2007. pdf/460433e6-3d66-400b-8e93-48413ea8203f>. Acesso em: jun. 2020.

Anvisa - Agência Nacional de Vigilância Sanitária. Codex Alimentarius, 2016. Disponível em: http://portal.Anvisa. gov.br/documents/33916/388701/Codex+Alimentarius/ 10d276cf-99d0-47c1-80a5-14de564aa6d3. Acesso em: jun. 2020.

Brandenburg, A. Movimento agroecológico: trajetória, contradições e perspectivas. Desenvolvimento e Meio Ambiente, 6, 11-28, 2002.
Brasil De Fato. 'Bolsa-agrotóxico': empresas recebem isenções de impostos de R $\$ 10$ bilhões ao ano, 2020. Disponível em: <https://www.brasildefato.com.br/2020/02/12/ bolsa-agrotoxico-empresas-recebem-isencoes-de-impostos-de-r-10-bilhoes-ao-ano>. Acesso em: out. 2020.

Banaszak, L. A. Inside and Outside the State: Movement Insider Status, Tactics, and Public PolicyAchievements. In: Meyer, D. S.; Jenness, V.; Ingram, H. Routing the Opposition: Social Movements, Public Policy, and Democracy. London: University Of Minnesota Press, 2005. p. 149-176.

Banaszak, L. A.; Ondercin, H. L. Explaining Movement and Countermovement Events in the Contemporary U.S. Women's Movement. In: Anais do American Political Science Association Meeting, 2010. Disponível em: https://papers. ssrn.com/sol3/papers.cfm?abstract_id $=1668884$. Acesso em: mar. 2020.

Bourdieu, P. O poder simbólico. Rio de Janeiro : Bertrand Brasil, 1989.

Bourdieu, P. A produção da Crença: contribuição para uma economia dos bens simbólicos. São Paulo: Zouk, 2002.

Bourdieu, P. O campo político. Revista Brasileira de Ciência Política, 5, 193-216, 2011.

Bruno, R. A. L. Elites agrárias, patronato rural e bancada ruralista. Texto para discussão. Observatório de Políticas Públicas para a Agricultura - OPPA, CPDA/UFRRJ, 2015. Disponível em: http://oppa.net.br/acervo/textos-fao-nead-gpac/Texto\%20de\%20conjuntura\%2009\%20-\%20Regina\%20BRUNO.pdf. Acesso em: abr. 2020.

Câmara dos Deputados. Projeto de Lei- PL 6299/2002e seus apensados, 2020. Disponível em: https://www.camara. leg.br/propostas-legislativas/46249. Acesso em: out. 2020.

Câmara dos Deputados. A voz do Brasil. Na Câmara, ministra da Agricultura defende liberação de agrotóxicos, 2019. Disponível em: <https://www.camara.leg.br/radio/ programas/555367-na-camara-ministra-da-agricultura-defende-liberacao-de-agrotoxicos/>. Acesso em: abr. 2020.

Campanha Permanente Contra os Agrotóxicos. Live\#1: Lançamento da Publicação “Agrotóxicos Perigosos”, 2020. Disponível em: https://youtu.be/wbW9mVmgPIY. Acesso em: ago. 2020. 
Canal Rural. Pelé será garoto propaganda de campanha da CNA, 2012. Disponível em: https://www.canalrural. com.br/noticias/pele-sera-garoto-propaganda-campanha-cna-35536/. Acesso em: jun. 2020.

Canavesi, F.C.; Moura, I. F,; Souza, C. Agroecologia nas políticas públicas e promoção da segurança alimentar e nutricional. Segurança Alimentar Nutricional, 23, 2016. Disponível em: https://periodicos.sbu.unicamp.br/ojs/index. php/san/article/view/8635617/14869

Carlos, E. Movimentos sociais e instituições participativas: Efeitos do engajamento institucional nos padrões de ação coletiva. Revista Brasileira de Ciências Sociais, 30 (88), 83-98, 2015. Disponível em: https://www.scielo.br/pdf/ rbcsoc/v30n88/0102-6909-rbcsoc-30-88-0083.pdf. Acesso em: mar. 2020.

Carneiro, F. F. Delgado, G; Augusto, L.G.S.; Almeida, V.S. Os impactos dos agrotóxicos na saúde, trabalho e ambiente no contexto do agronegócio no Brasil, 2012. Disponível em http://www.saudecampofloresta.unb.br/wp-content/uploads/2014/03/Os-impactos-dos-agrotóxicos-na-saúde-trabalho-e-ambiente-no-contexto-do-agronegócio-no-Brasil. pdf. Acesso em: abr. 2020.

De Carli, C. O discurso político da agroecologia no MST: O caso do Assentamento 17 de Abril em Eldorado dos Carajás, Pará. Revista Crítica de Ciências Sociais, 100, 2013. Disponível em: http://journals.openedition.org/rccs/5245

Diniz, P.; Rozendo, C. Panorama da Política Nacional de Agroecologia e Produção orgânica na última década. Agroecologia - Boletim da Sociedade Brasileira de Economia Ecológica (ECOECO), 39, 53-61, 2019.

Ecodebate. Entrevista com Susana Prizendt, coordenadora da Campanha Permanente Contra os Agrotóxicos no estado de São Paulo, 2012. Disponivel em: https://www.ecodebate. com.br/2012/12/10/entrevista-com-susana-prizendt-coordenadora-da-campanha-permanente-contra-os-agrotoxicos-no-estado-de-sao-paulo/ Acesso em: jun. 2020.

Estadão. Rabbelo, J. B. Enredo da Mocidade Independente, em 2011, prega a convivência entre o agronegócio e o meio-ambiente. Estadão, 25, 2010. Disponível em:https:// politica.estadao.com.br/blogs/joao-bosco/enredo-da-mocidade-independente-em-2011-prega-convivencia-entre- -o-agronegocio-e-o-meio-ambiente. Acesso em: jun. 2020.

Exame. Agronegócio brasileiro deve virar marca global, 2017.Disponível em: https://exame.com/marketing/agronegocio-brasileiro-deve-virar-marca-global-diz-nizan-guanaes/. Acesso em: abr. 2020.

Exame. Tereza Cristina convoca agronegócio para "ganhar guerra da comunicação”, 2019. Disponível em: https:// exame.com/brasil/ministra-chama-membros-do-agronegocio-para-ganhar-guerra-da-comunicacao. Acesso em: out. 2020.

Folha de São Paulo. Nenhum consumidor brasileiro está sendo intoxicado', diz ministra da Agricultura sobre agrotóxicos, 2019. Disponivel em: https://www1.folha.uol.com. br/ambiente/2019/08/nenhum-consumidor-brasileiro-esta-sendo-intoxicado-diz-ministra-da-agricultura-sobre-agrotoxicos.shtml. Acesso em: abr. 2020.

Franco, C. da R.; Pelaez, V. A (des)construção da agenda política de controle dos agrotóxicos no Brasil. Ambiente \& Sociedade, XIX(3), 215-232, 2016.

Frente parlamentar ambientalista. Ação tramitando no STF desde 2016 lembra que produtos provocam danos à saúde e ao meio ambiente, 2020. Disponível em: https://www. frenteambientalista.com/adi-5553/. Acesso em: out. 2020.

G1. Kátia Abreu quer tirar da Anvisa registro de produtos agropecuários, 2015.Disponivel em: https://revistagloborural.globo.com/Noticias/Politica/noticia/2015/09/ katia-abreu-quer-tirar-da-Anvisa-registro-de-produtos-agropecuarios.html. Acesso em: jun. 2020.

Graziano da Silva, J. A modernização dolorosa. Rio de Janeiro: Zahar, 1982.

IstoÉ. Aprosoja se desliga da Abag apontando diferenças de interesses e objetivos. 2020. Disponível em: https:// www.istoedinheiro.com.br/aprosoja-se-desliga-da-abag-apontando-diferencas-de-interesses-e-objetivos/. Acesso em: out. 2020.

Jornal da USP. Lançado na Europa mapa do envenenamento de alimentos no Brasil, 2019. Disponível em: https://jornal. usp.br/ciencias/ciencias-ambientais/lancado-na-europa-mapa-do-envenenamento-de-alimentos-no-brasil/. Acesso em: out. 2020. 
Lerrer, D. F. Revista Agroanalysis: a trajetória da formação do "agronegócio" e da consagração de seus agentes. Contemporanea - Revista de Sociologia da UFSCar, 10(1), 273-304, 2020.

Lo, C. Y. H. Countermovements and Conservative Movements in the Contemporary U.S. Annual Review of Sociology, 8, 107-134, 1982.

Luzzi, N. O debate agroecológico brasileiro: uma discussão a partir dos EBAAS e da experiência do PTA/FASE. In: Anais do Encontro Anual da ANPOCS, Caxambu, 15 jun., 2008.

Meyer, D. S.; Staggenborg, S. Movements, Countermovements, and the Structure of Political Opportunity. American Journal of Sociology, 101(6), 1628-1660, 1996.

Mitidiero, M. A.; Barbosa, H. N.; Sa, T. H. de. Quem produz para os brasileiros? 10 anos do Censo Agropecuário de 2006. Revista Pegadas, 1-71, 2017.

MMA-Ministério do Meio Ambiente. Empresas terão de se adaptar à Lei dos Agrotóxicos, 2000. Disponível em: https:// www.mma.gov.br/informma/item/1040-empresas-terao-de-se-adaptar-a-lei-dos-agrotoxicos. Acesso em: jun. 2020.

Notícias Agrícolas. Campanha do movimento Sou Agro estreou nos meios de comunicação, 2011. Disponível em: https://www.noticiasagricolas.com.br/noticias/agronegocio/92767-campanha-do-movimento-sou-agro-estreia-nos-meios-de-comunicacao.html\#.XvxtcZNKi8V. Acesso em: 24 jun 2020.

Pereira, M. M. Trazendo os governos de volta: a chefia do executivo e os resultados do ativismo institucional LGBT (2003-2014). Sociologias, 22(53), p. 228-263, 2020.

Polletta, F.; Gardner, B. G. Narrative and Social Movements. In: Della Porta, D.; Diani, M. The Oxford Handbook of Social Movements. Oxford Press, p.534-548, 2015.

Porto M. F. de S. O trágico Pacote do Veneno: lições para a sociedade e a saúde Coletiva. Cadernos de Saúde Pública, 34(7), 01-05, 2018.

Repórter Brasil. 'Musa do veneno', a deputada Tereza Cristina recebe doações de empresários ligados a agrotóxicos, 2018. Disponível em: https://reporterbrasil.org. br/2018/09/musa-do-veneno-deputada-tereza-cristina-rece- be-doacoes-de-empresarios-ligados-a-agrotoxicos/. Acesso em: out. 2020.

Rozendo, C. Políticas ambientais, agricultura familiar e a recomposição dos espaços rurais na região metropolitana de Curitiba. Curitiba, Tese (Doutorado em Meio Ambiente e Desenvolvimento) - UFPR, 2006.

Sabourin, E.; Craviotti, C.; Milhorance; C. The Dismantling of Family Farming Policies in Brazil and Argentina. International Review of Public Policy, 2(1), 45-67, 2020.

Silva M. K. Contramovimentos Sociais no Brasil? Especificidades da conflitualidade social em um país de desigualdades extremas. No prelo, 2020.

Silva, M. K.; Pereira, M.M. Movimentos e Contramovimentos Sociais: o caráter relacional da conflitualidade social. No prelo, 2020.

Silva, M. K.; Oliveira, G. A face oculta(da) dos movimentos sociais: trânsito institucional e intersecção Estado-Movimento - uma análise do movimento de Economia Solidária no Rio Grande do Sul. Sociologias, 13(28), 86-124, 2011.

Startagro. Por que a Globo criou a campanha "Agro é Tech, Agro é Pop”, 2017. Disponível em: http://www.startagro. agr.br/por-que-o-agronegocio-precisa-de-uma-comunicacao-moderna/Acesso em: abr. 2020.

Stoppelli, I. M. De B.S. Magalhães, C. P. Saúde e segurança alimentar: a questão dos agrotóxicos. Ciência \& Saúde Coletiva, 10, 91-100, 2005. Disponível em: http://www. scielo.br/scielo.php

Szwako, J. “O ‘mau desempenho’ de Lugo: gênero, religião e contramovimento na última destituição presidencial paraguaia”. Opinião Pública, 20(1), 132-155, 2014.

Thiry-Cherques, H. R. Pierre Bourdieu: a teoria na prática. RAP, 40(1), 27-55, 2006.

TV Senado. Sen. Kátia Abreu diz que agrotóxicos baixam os preços e propõe que Ministro da Saúde seja convocado, 2010. Disponível em:https://www.youtube.com/watch?v=QXqMKBniNSk. Acesso em: jun. 2020.

UOL. O que muda com o projeto de lei de agrotóxicos em discussão no Congresso?, 2018. Disponível em https:// noticias.uol.com.br/meio-ambiente/ultimas-noticias/reda- 
cao/2018/07/12/o-que-muda-com-o-projeto-de-lei-de-agrotoxicos-em-discussao-no-congresso.htm?. Acesso em: out. 2020 .

UOL. Isenção a agrotóxico é quase 4 vezes a verba do Ministério do Meio Ambiente, 2020. Disponivel em: https://noticias.uol.com.br/meio-ambiente/ultimas-noticias/ reporter-brasil/2020/02/12/isencao-a-pesticidas-e-quase-4-vezes-a-verba-do-ministerio-do-meio-ambiente.htm?fbclid=IwAR0TuxUVNi6Fi_yjvXwP1ZcsNzS8obkOdU7p8x2-1IRcUzVv_t-v_heYD18\&c. Acesso em: out. 2020.

Vaggione, J. M Reactive politicization and religious dissidence: the political mutations of the religious. Social Theory and Practice, 31(2), 233-255, 2005.

Wanderley, M. de N. B. O campesinato brasileiro: uma história de resistência. Revista de Economia e Sociologia Rural, 52(1), 25-44, 2014. doi: 10.1590/S010320032014000600002

Wolford, W.; Sauer S. Authoritarian elitism and popular movements in Brazil. Open Democracy, 2018. Disponível em: https://www.opendemocracy.net/en/authoritarian-elitism-and-popular-movements-in-brazil/. Acesso em: maio 2020. 